\title{
Schizoid Personality Traits Among the Homeless Mentally Ill: A Quantitative and Qualitative Report
}

\author{
Lisa Rouff ${ }^{1}$
}

This paper examines the interplay among schizoid personality traits, chronicity of homelessness, and engagement in treatment in a homeless mentally ill population. Both qualitative and quantitative information will be provided about a sample of 125 homeless mentally ill individuals receiving psychiatric treatment in a comprehensive services drop-in clinic. Naturalistic observations and a case vignette suggested that schizoid traits were prevalent and may have been playing a role in treatment engagement and chronicity of homelessness. This hypothesis was tested using quantitative research methods. The results showed that schizoid personality disorder and schizoid personality traits were prevalent in the sample. The presence of schizoid traits was positively correlated with chronicity of homelessness. Further, two schizoid traits (being content without sexual involvement with others, and lacking close friends or confidants) were positively correlated with remaining in treatment at 3 months. Implications of these findings for future research and treatment design will be discussed.

KEY WORDS: homeless mentally ill; schizoid personality disorder.

\section{INTRODUCTION}

Eliminating homelessness among the mentally ill presents a considerable challenge. The homeless mentally ill population is increasing and currently numbers between 150,000 and 500,000 individuals (Jencks, 1994; Link et al., 1995; National Coalition for the Homeless, 1999; Robertson, 1986; Rossi, Wright, Fisher, $\&$ Willis, 1987). Although considerable money and effort have been expended to help the homeless mentally ill, their problems continue to persist. This may be

${ }^{1}$ Correspondence should be directed to Lisa Rouff, Ph.D., University of Michigan Medical Center, Riverview Building 900 Wall Street, Ann Arbor, MI 48109; e-mail: rouff@umich.edu. 
because many homeless mentally ill individuals do not utilize psychiatric and social services (Bachrach, Santiago, \& Berren, 1990; Caton, 1995; Hannappel, Calsyn, \& Morse, 1989; Harris \& Bachrach, 1990; Morse \& Calsyn, 1986; Passero, Zax, \& Zozus, 1991; Scott, 1993). Further, once the homeless mentally ill do enter treatment or housing programs, they are likely to terminate treatment prematurely, with drop-out rates ranging from 41 to $74 \%$ (Burling, Seidner, Salvio, \& Marshall, 1994; Morse, Calsyn, Allen, \& Kenny, 1994; Murray, Baier, North, Lato, \& Eskew, 1995; Orwin, Sonnefeld, Garrison-Mogren, \& Smith, 1994; Rosenheck \& Leda, 1991; Rosenheck, Leda, \& Gallup, 1993; Slagg, Lyons, Cook, Wasner, \& Ruth, 1994).

Some problems in effectively treating the homeless mentally ill stem from difficulty in conducting research with this population. For example, it is very difficult to even know the approximate number of homeless mentally ill individuals because of the difficulty finding and counting individuals with no set abode or life patterns (National Coalition for the Homeless, 1999). In addition, the homeless mentally ill, even when available for research, are often considered to be poor and inaccurate historians (Schumacher, Milby, Raczynski, \& Caldwell, 1995). Another complicating factor is that the homeless mentally ill population is made up of several distinct subgroups, such as homeless men, homeless women, homeless families, survivors of childhood abuse, veterans, and so on (Burke, Rouff, \& Shelby, 1997; Burt \& Cohen, 1989; Kuhn \& Culhane, 1998). Each of these groups has different characteristics and may have different needs for housing and treatment. This heterogeneity makes it even more difficult to understand what factors affect treatment and housing stability for the homeless mentally ill population.

Given the difficulties inherent in studying the homeless mentally ill, it may be beneficial to study particular subgroups of the population using more than one method of data collection to maximize the types and accuracy of information obtained. There are several advantages to combining qualitative and quantitative approaches when studying a complex population such as the homeless mentally ill. Because the homeless mentally ill are a difficult population to recruit for research, when a large enough sample is obtained, it is advantageous to use different types of research designs simultaneously in order to maximize the amount of information collected. Such a combined method provides more rich and in-depth information. For example, it provides clinically relevant information about research subjects, allowing collection of information similar to that which clinicians would be presented. The findings may therefore be more relevant to clinical settings than traditional research approaches. Further, conducting research in a more naturalistic way, without experimental manipulation, may be helpful in observing what actually happens with these difficult to treat individuals. In addition, using both quantitative and qualitative information from a clinical setting aids in hypothesis generation, which is particularly useful when researching a complex problem for which no clear answers have yet emerged. 
In this vein, this paper provides information collected using both quantitative and qualitative methods about a particular subgroup of homeless mentally ill individuals, those who utilize a specific type of psychiatric treatment. The study will focus on the difficulties a group of homeless mentally ill individuals receiving treatment at a psychiatric services drop-in center in downtown Chicago, experienced in remaining engaged in psychiatric treatment and housing programs. Studying this subgroup, although limiting the study's generalizability in regard to the general homeless population, provides more in-depth and detailed information about those homeless mentally ill most likely to have contact with treatment providers. Also, it was possible to observe research subjects in a variety of contexts and over time, in contrast to other studies that collect data in several different types of settings at periodic intervals. This will provide information particularly relevant for clinicians working with this population and will also aid in the design of more effective housing and treatment options.

Both qualitative observations and quantitative data from the sample collected over a 2-year period will be provided. Qualitative observations focused on the difficulty the clinic participants exhibited in consistently engaging in psychiatric treatment and/or appropriate housing. Many clinic participants, as will be discussed below, seemed aloof, distant, and uninterested in establishing or maintaining interpersonal relationships. These observations led to the generation of a new hypothesis, that schizoid personality traits may have been playing a role in treatment engagement and chronicity of homelessness. Theoretical underpinnings of this hypothesis will be presented, as well as a brief clinical and research vignette illustrative of these dynamics. Finally, quantitative data will be presented showing that schizoid personality traits affect chronicity of homelessness and treatment engagement, albeit in surprising ways.

\section{PART ONE: QUALITATIVE OBSERVATIONS}

This study was conducted in the NWHOME Clinic, a HUD funded drop-in comprehensive services psychiatric clinic located in a local YMCA in downtown Chicago. Many homeless mentally ill individuals stayed at the YMCA from time to time or visited it to buy drugs. In addition, it was within walking distance of several single resident occupancy hotels and shelters. Psychiatrists, social workers, psychiatric nurses, mental health workers, and occupational therapists staffed the clinic. Services offered included medication management, case management, individual therapy, group therapy, and occupational therapy groups such as cooking and other life skills, as well as music, art, and gardening groups. For most services, appointments were not necessary. When patients dropped by, they were offered individual services as needed, and if a group was running at the time, they were invited to join. Behaviors normally not allowed in traditional treatment 
settings, such as ranting, acting strangely, or being intoxicated, were tolerated in the NWHOME clinic.

The clinic attracted clients by posting signs in the YMCA itself advertising that the clinic offered snacks and services, through referrals from local shelters, emergency rooms, and psychiatric hospitals. Other organizations in the city that worked with the homeless also brought patients to the clinic.

The research was part of a larger treatment grant provided by the Department of Housing and Urban Development. The research program consisted of a 2-hour intake interview (used for part of a larger study) and follow-up interviews at 3-month intervals. The interviews, conducted by clinical psychology graduate students, used both interview and written questionnaires. Research participants were rewarded with fast food gift certificates at completion of the interviews.

Although approximately $95 \%$ of NWHOME patients agreed to do the research interview, only about $50 \%$ actually participated. This was mainly because they came to the clinic one or two times and never returned. Once gone, they were difficult to contact-usually, they had left their shelter or transitional housing program for parts unknown. Despite concerted efforts to track down research participants, the follow up rate was 30 to $40 \%$.

Most research subjects behaved appropriately during the interview. Two participants left the interview once they were asked questions other than their name and age, stating they did not want to give out such personal information. About half of the participants were malodorous, and about a third smelled of alcohol.

A few of the participants, who had followed through with the project, seemed to be attached and involved in the interview process, frequently asking when they could have their next follow-up interview. It was clear that they looked forward to the interpersonal contact and to receiving a fast food gift certificate. However, the majority of patients and research subjects seemed aloof and distant. They would enter treatment and housing programs and then vanish quickly, only to reappear a few months later and then disappear again. Many of these individuals appeared quite withdrawn socially, preferring to be alone to staying in a crowded shelter. They also seemed uninterested in staying in psychiatric treatment or case management despite their distressing symptoms and squalid living conditions. It appeared that fear of or discomfort with contact with others might be playing a role.

More specifically, these characteristics are similar to the concept of the schizoid position described in the object relations theories of Fairbairn and Guntrip. For Fairbairn and Guntrip, the schizoid position was an attempt to "cancel external-object relations and live in a detached and withdrawn way" (Guntrip, 1961, p. 19). In other words, the schizoid person acts as if they have no need for or interest in contact with others, despite underlying longings and needs for such contact. Fairbairn (1952) and Guntrip (1961) both believed the need to be loved and have social contact with others was innate and a profound motivator of human 
behavior. For schizoid persons, early neglect or mistreatment by others created intense unmet needs for love and social contact, and correspondingly, much frustration and rage. The schizoid person unconsciously fears that the expression of this rage and longing will get out of control-thus, he or she avoids contact with others altogether, which would produce this longing.

Guntrip believed that this withdrawn and detached state could only last so long before the schizoid individual's longings would eventually break through enough to motivate him to initiate contact with others. Once in contact with others, even more longing and rage is evoked and in response, the schizoid person quickly flees the interpersonal contact again. Guntrip termed this the "in and out" program.

The concepts of schizoid personality traits and the "in and out" program seemed to fit the behavior I observed. The case example of Mr. A., a NWHOME patient and research participant, illustrated these behaviors.

Mr. A was an African American man in his late 40s. He had a long history of living on the street and using alcohol and cocaine. His long periods of homelessness were occasionally punctuated with psychiatric hospitalizations, as he also suffered from schizophrenia, although his psychotic symptoms were well controlled when he was compliant with his medication. Despite numerous efforts by social workers and caseworkers in the past, Mr. A always rapidly returned to homelessness after discharge from the state hospital. One day, Mr. A uncharacteristically agreed to talk to a social services worker. The agency housed him in an single residence occupancy hotel and brought him to the clinic. He was quite suspicious and did not want to receive psychiatric medications, much less participate in an extensive research interview. He disappeared from treatment for months at a time. Surprisingly, during one of his early visits, he allowed me to interview him. He was quiet, giving one-word answers for most of the interview. At the end, he smiled fleetingly and thanked me. He began to come to the clinic occasionally to sit and eat, but would quickly leave if approached by anyone to join a group. Gradually, over the course of a year, he became somewhat more regularly involved and agreed to receive antipsychotic injections. He also agreed to participate in research follow-up interviews. As I prepared to leave my job, I mentioned to him that I would be leaving and he would now be followed by my replacement. To my surprise, tears welled up in his eyes, and he said that if he had a gun, he would kill me. He promptly disappeared again from the clinic for 2 months, but did come back (and did continue in the research program).

Mr. A. seemed to exemplify some schizoid personality traits. He lived his life in a predominantly detached way, yet it was clear that he had need for contact with others. It also seemed clear that these longings for contact with others, and his rage when these longings were not satisfied, disturbed him and caused him to leave interpersonal situations. 
In addition to these qualitative observations, other research on the homeless mentally ill lends indirect support to the "schizoid hypothesis." One common finding is that the homeless mentally ill are quite socially isolated and lack adequate social support (Fisher, Shapiro, Breakey, Anthony, \& Kramer, 1986; Scott, 1993). The homeless mentally ill are also very unlikely to be married or to have extensive contact with family members (Fisher et al., 1986; Scott, 1993). Further, other research studies suggest that schizoid personality traits may be functioning independently of schizophrenia or other Axis I disorders. Although schizoid personality disorder is often thought to be related to schizophrenia, several studies have shown that the presence of schizoid personality disorder or traits is not significantly associated with a diagnosis of schizophrenia (Longabaugh \& Eldred, 1973; Mellsop, 1973; Nestad, Liang, Lamacz, 1994; Torgalsboen, 1999).

Given observations of research participants like Mr. A, and collateral support from the literature, the use of quantitative methods and statistical analyses to test the qualitatively-driven hypotheses that schizoid traits were prevalent among this sample and were affecting housing stability and treatment engagement seemed appropriate. Because the theories of Fairbairn and Guntrip focus primarily on unconscious dynamics, a pilot study using a projective scoring technique for intimacy motivation was performed (McAdams, 1992). In this method, research participants are shown TAT-like cards that display two human figures and are asked to tell a story about the picture. After 10 subjects, it became clear that this method would not work because none of the subjects could provide projective stories about the two figures. A common response would be to comment on the inanimate objects in the picture and then refuse to go further. Although these responses seemed like important information, it was not possible to use them for a quantitative research study.

Instead, the more overt symptoms of schizoid personality disorder, as defined by the SCID-II, were used to measure the construct of schizoid personality traits. These traits are:

A pervasive pattern of detachment from social relationships and a restricted range of expression of emotions in interpersonal settings, beginning by early adulthood and present in a variety of contexts, as indicated by at least four of the following:

1. neither desires nor enjoys close relationships, including being part of a family

2. almost always chooses solitary activities

3. has little, if any interest in having sexual experiences with another person

4. takes pleasure in few, if any, activities

5. lacks close friends or confidants other than first degree relatives

6. appears indifferent to the praise or criticism of others

7. shows emotional coldness, detachment, or flattened affectivity (APA, 1994, p. 641)

Next, the quantitative exploration of the possible interplay between schizoid traits, chronicity of homelessness, and engagement in treatment will be described in more detail. 


\section{PART TWO: QUANTITATIVE DATA}

\section{Hypotheses}

The hypotheses of the study were that homeless mentally ill individuals with schizoid traits would have a higher level of chronicity of homelessness and would be more likely to prematurely terminate psychiatric treatment. These hypotheses were tested using the following questions:

1. What was the prevalence of schizoid traits among this sample?

2. Was the presence of schizoid traits associated with chronicity of homelessness?

3. Was the presence of schizoid traits associated with engagement in treatment?

\section{METHOD}

\section{Sample}

Research participants were 125 homeless mentally ill individuals in the Chicago metropolitan area recruited from Northwestern Memorial Hospital's NWHOME Project, a HUD funded psychiatric clinic located within a local YMCA, as described above.

Research interviews were conducted as soon as possible after participants' registration in the clinic. The 125 participants were administered a series of oral and written questionnaires in an interview that lasted approximately 2 hours as described above. Clinical psychology graduate students conducted the interviews with acceptable inter-rater reliability $\left(r_{k}=.73\right)$.

\section{Measures}

\section{Schizoid Traits}

The Structured Clinical Interview for DSM-III-R Personality Disorders, or the SCID-II (First, Spitzer, Gibbon, \& Williams, 1995), is a semistructured interview that provides an assessment of the presence of eleven DSM-III-R Axis II disorders. For present purposes, only the data collected on schizoid personality disorder was used. The SCID-II has two components, a self-report screening questionnaire and an interview. It has reliability and validity rates (.56 to .64) consistent with other measures of personality disorders, but is more commonly used because it is easier and faster to administer (First et al., 1995). Further, the SCID-II allows interviewers to collect information about personality disorder symptoms that are present, but 
are not by themselves enough to warrant a diagnosis of a personality disorder (First et al., 1995).

\section{Chronicity of Homelessness}

The Personal History Interview (Susser, 1991) was developed to collect baseline information of participants' history of homelessness and psychiatric illness. Two questions from this questionnaire measured chronicity of homelessness: participants' length of time homeless and total number of times homeless. Homelessness is defined in this questionnaire as either staying at a shelter or sleeping outside.

\section{Treatment Status}

To collect information on participants' engagement in the clinic, a chart review was conducted to determine their treatment status 3 months after their initial contact with the clinic.

\section{Statistical Analyses}

To assess the prevalence of schizoid traits in the sample, the percentage of individuals who possessed schizoid personality disorder and each of the seven schizoid traits was calculated. To determine if a higher number of schizoid traits was associated with a higher number of times homeless, a partial correlation was used, controlling for age. Another partial correlation analysis, controlling for age, was then performed, to determine whether a higher number of schizoid traits were associated with length of time homeless. These analyses were repeated for each of the individual schizoid traits.

To determine whether number of schizoid traits was associated with engagement in treatment, a point biserial correlation was used. Chi-square analyses were also performed to find the level of association between individual schizoid traits and treatment status.

A one-tailed significance value of 0.05 was used for all of the above analyses. Because of missing data, the size of the groups varied from one statistical analysis to another.

\section{RESULTS}

\section{Demographics}

The participants were predominantly male (68.8\%), African American $(49.6 \%)$, and currently single $(94.4 \%)$. Mean age was 39.12 years old $(S D=9.82)$. Further demographic information is listed in Table I. 
Table I. Demographics of a Sample of Homeless Individuals Seeking Psychiatric Treatment $(n=125)$

\begin{tabular}{lrr}
\hline \multicolumn{1}{c}{ Characteristic } & Number & Percent \\
\hline Sex & & \\
$\quad$ Male & 86 & 68.8 \\
$\quad$ Female & 39 & 31.2 \\
Ethnicity & & \\
$\quad$ African American & 62 & 49.6 \\
$\quad$ Caucasian & 50 & 40.0 \\
Latino & 3 & 2.4 \\
$\quad$ Other & 10 & 8.0 \\
Marital status & & \\
$\quad$ Single & 89 & 73.0 \\
Married & 3 & 2.4 \\
$\quad$ Separated/divorced & 29 & 23.8 \\
$\quad$ Widowed & 1 & .8 \\
Children & & \\
$\quad$ No & 69 & 55.6 \\
$\quad$ Yes & 55 & 44.4 \\
Education & & \\
$\quad$ Less than high school & 39 & 32.5 \\
$\quad$ High school graduate & 31 & 25.8 \\
$\quad$ Some college & 37 & 30.9 \\
$\quad$ College graduate & 13 & 10.8 \\
\hline
\end{tabular}

\section{Other Psychiatric Diagnoses}

A significant percentage of research participants were diagnosed with psychotic disorders (62\%), affective disorders (40\%), and substance abuse disorders (76.5\%). The most prevalent Axis II disorders, other than schizoid personality disorder, were paranoid personality disorder (38\%), antisocial personality disorder $(19 \%)$, schizotypal personality disorder $(18.2 \%)$, and borderline personality disorder $(12.4 \%)$.

\section{Homelessness History}

Most participants had experienced one to four separate incidences of homelessness (83.8\%) and had spent over 3 months being homeless (63.6\%). See Table II for more specific information regarding their homelessness history.

\section{Prevalence}

Fourteen percent of the sample was diagnosed with schizoid personality disorder, defined by the SCID-II as the presence of five schizoid traits. The prevalence rates of specific schizoid traits ranged from 13.6 to $45.4 \%$ and are listed in Table III. 
Table II. History of Homelessness in a Sample of Homeless Individuals Seeking Psychiatric Treatment

\begin{tabular}{lcr}
\hline & Number & Percent \\
\hline Number of times homeless $(n=117)$ & & \\
$\quad$ One & 64 & 54.7 \\
Two to four & 34 & 29.1 \\
Five to nine & 12 & 0.3 \\
Ten or more & 7 & 6.0 \\
Length of time homeless $(n=121)$ & & \\
$\quad$ Less than three months & 44 & 36.4 \\
Three to twelve month & 29 & 24.0 \\
One to three years & 25 & 20.7 \\
Three to six years & 12 & 9.9 \\
Over nine years & 11 & 9.1 \\
\hline
\end{tabular}

Table III. Prevalence of Specific Schizoid Traits Among a Sample of Homeless Individuals Seeking Psychiatric Treatment $(n=119)$

\begin{tabular}{lcc}
\hline \multicolumn{1}{c}{ Trait } & Number & Percent \\
\hline Neither desires or enjoys close relationships & 44 & 37.0 \\
Almost always chooses solitary activities & 48 & 40.3 \\
No strong feeling experienced & 30 & 25.2 \\
Content without sexual involvement with another person & 54 & 45.4 \\
Indifferent to praise or criticism & 30 & 25.2 \\
No close friends or confidants & 36 & 30.3 \\
Displays constricted affect (as rated by an observer) & 16 & 13.4 \\
\hline
\end{tabular}

Note. The total percentage of traits exceeds $100 \%$ because participants can possess more than one trait.

\section{Chronicity of Homelessness}

Number of schizoid traits present was significantly correlated with length of time homeless $(r=.194, p=.02, n=114)$ but not with number of times homeless $(r=.141, p=.07, n=114)$.

Only one schizoid trait, constricted affect $(r=.179, p=.03, n=113)$ was significantly correlated with the number of times homeless. Two specific schizoid traits were significantly correlated with length of time homeless: preferring to do things alone rather than with other people $(r=.219, p=.01, n=113)$; and constricted affect $(r=.155, p=.05, n=113)$.

\section{Engagement in Treatment}

Schizoid and non-schizoid participants did not differ in their rates of treatment engagement. Number of schizoid traits present was not significantly correlated with premature termination $(r=.097, p=.17, n=103)$. The presence of two schizoid 
traits was positively associated with remaining in treatment at 3 months: being content without sexual involvement $\left(\chi^{2}(1, n=96)=5.752, p<.01\right)$; and having no close friends or confidants $\left(\chi^{2}(1, n=96)=7.124, p<.01\right)$.

\section{DISCUSSION}

\section{Prevalence}

The prevalence rate of schizoid personality disorder (14\%) for this sample of homeless individuals is higher than most reported prevalence rates for both community and psychiatric populations, which average around 1\% (First et al., 1995; Kalus, Bernstein, \& Siever, 1993; Reich, Yates, \& Nduaguba, 1989; Zimmerman \& Coryell, 1990). This is an important finding in that it suggests that the homeless mentally ill population may have a higher than normal prevalence of schizoid personality disorder.

Despite this, there was no association between a diagnosis of schizoid personality disorder and chronicity of homelessness or engagement in treatment. However, the presence of specific schizoid traits was related to chronicity of homelessness and engagement in treatment. Further, specific schizoid traits in the sample were quite common ( $77 \%$ of the sample had at least one schizoid trait). This may indicate that even the presence of a few schizoid traits could impact housing status or treatment engagement.

\section{Chronicity of Homelessness}

The hypothesis that schizoid traits were correlated with chronicity of homelessness was supported in some respects. The number of schizoid traits possessed was significantly and positively correlated with chronicity of homelessness. These findings may be explained by the specific traits significantly correlated with chronicity of homelessness (displaying constricted affect and preferring to do things alone). Individuals who possess both these traits may be more likely to have other serious mental illnesses, such as schizophrenia, which could negatively affect their ability to maintain consistent housing. However, post-hoc analyses revealed no significant correlations between the presence of any schizoid traits and any other Axis I or Axis II disorder.

Also, the trait of displaying constricted affect was the only trait is based solely on interviewer judgment rather than self-report. Perhaps the interviewer observed something about the participants that they themselves did not-such as the extent of their schizoid or isolative tendencies.

Further, schizoid traits were more frequently associated with length of time spent homeless rather than number of times homeless. This may indicate that 
schizoid individuals do not tend to move in and out of housing situations frequently, but remain homeless for longer uninterrupted periods of time.

\section{Engagement in Treatment}

The hypothesis regarding engagement in treatment was not supported. Indeed, participants with two particular schizoid traits (being content without sexual involvement, and lacking close friends or confidants) were more likely to remain in treatment. The nature of the NWHOME program itself may be responsible for these findings. As reported above, clinicians at the NWHOME program tolerate a wide range of behaviors that would not be acceptable in many treatment settings. This setting, which allows patients to come in and out of treatment when they wish and in almost any condition, may better engage schizoid individuals. The 3-month engagement rate for NWHOME, 57\%, is higher than other treatment programs described in the literature, which have retention rates between 16 to $50 \%$ (Morse et al., 1994; Rosenheck \& Leda, 1991; Rosenheck, Leda, \& Gallup, 1993). Thus, the NWHOME program's format may provide a solution to the problem the study addressed.

Both traits associated with remaining in treatment reflect a tendency toward social isolation. Perhaps, homeless mentally ill individuals, who frequently lead lives of social and physical deprivation, come to treatment feeling so depleted that they become frustrated and drop out if all of their interpersonal needs are not quickly met. Possibly, homeless mentally ill individuals who prefer social isolation are in some ways better defended psychologically and can better tolerate the boundaries of the therapeutic relationship.

In summary, schizoid traits are quite common among the homeless mentally ill and are associated with chronicity of homelessness and engagement in treatment. However, methodological issues of the study need to be considered when interpreting the results. For instance, sampling problems may have prevented finding more robust results. This study used volunteer homeless mentally ill individuals who sought treatment. As the most socially isolated homeless mentally ill individuals do not seek treatment, the sample may have not included many of the most schizoid individuals. Using a more restricted range of homeless individuals may have artificially lowered the association between schizoid traits and chronicity of homelessness in this study. Further, measurement difficulties may have also been a factor in the study. The quantitative findings in this study relied on self-report measures for both the presence of schizoid traits and chronicity of homelessness, and some evidence shows that the homeless mentally ill are poor historians (Schumacher et al., 1995). Also, some researchers have suggested that the diagnostic criteria of DSM-III-R personality disorders are problematic, citing problems with overlapping criteria and the use of self-report in diagnosing personality disorders (Westen, 1997; Widiger \& Rogers, 1989). Additional 
research on this topic with nonvolunteer based samples and multiple measures for schizoid traits and homelessness history may be beneficial to further clarify the relationship between schizoid traits, chronicity of homelessness, and engagement in treatment.

\section{CONCLUSIONS}

This study suggests that schizoid personality traits affect homelessness, highlighting the importance of adding personality traits to the list of variables that affect homelessness and its treatment. Clearly, homelessness is not merely a social or economic problem, but a complex interplay of social issues, housing issues, psychiatric conditions, and personality characteristics. The findings of this study provide additional evidence that personal and psychiatric characteristics of the homeless mentally ill should be studied to better understand their difficulties engaging in treatment and maintaining housing. To best understand this complex population, it also seems helpful to conduct research that uses a variety of methods and perspectives, both qualitative and quantitative, including naturalistic research projects conducted on subgroups of the homeless mentally ill population in many types of settings. Also, single-subject case studies may provide helpful information that will aid in hypothesis generation. In this way, we may find more effective methods to engage and treat the homeless mentally ill and to reduce the prevalence of homelessness in our society.

\section{REFERENCES}

American Psychiatric Association. (1994). Diagnostic and statistical manual of mental disorders (4th ed.). Washington, DC: Author.

Bachrach, L., Santiago, J., \& Berren, M. (1990). Homeless mentally ill patients in the community: Results of a general hospital emergency room study. Community Mental Health Journal, 26, $415-423$.

Burke, N., Rouff, L., \& Shelby, S. (1997, October). Abuse as a precursor to intensified distress among the homeless. Paper presented at the American Psychiatric Association Annual Convention, Washington DC.

Burling, T., Seidner, A., Salvio, M., \& Marshall, G. (1994). A cognitive-behavioral therapeutic community for substance dependent and homeless veterans: Treatment outcome. Addictive Behaviors, $19,621-629$.

Caton, C. (1995). Mental health service use among homeless and never-homeless men with schizophrenia. Psychiatric Services, 46, 1139-1143.

Fairbairn, W. (1952). Psychoanalytic studies of the personality. London: Routledge \& Kegan Paul.

First, M., Spitzer, R., Gibbon, M., \& Williams, J. (1995). The structured clinical interview for DSMIII-R personality disorders (SCID-II). Part I: Description. Journal of Personality disorders, 9, 83-91.

First, M., Spitzer, R., Gibbon, M., Williams, J., Davies, M., Borus, J., Howes, M., Kane, J., Pope, H., \& Rounsaville, B. (1995). The structured clinical interview for DSM-III-R personality disorders (SCID-II). Part II: Multi-site test-retest reliability study. Journal of Personality Disorders, 9, 92-104. 
Fischer, P., Shapiro, S., Breakey, W., Anthony, J., \& Kramer, M. (1986). Mental health and social characteristics of the homeless: A survey of mission users. American Journal of Public Health, 76, 519-524.

Guntrip, H. (1961). Personality structure and human interaction: The developing synthesis of psychodyamic theory. New York: International Universities Press.

Hannappel, M., Calsyn, R., \& Morse, G. (1989). Mental illness in homeless men: A comparison of shelter and street samples. Journal of Community Psychology, 17, 304-310.

Jencks, C. (1994). The Homeless. Cambridge: Harvard University Press.

Kalus, O., Bernstein, D. P., \& Siever, L. J. (1993). Schizoid personality disorder: A review of current status and implications for DSM-IV. Special Feature: DSM-IV reviews of the personality disorders: III. Journal of Personality Disorders, 7, 43-52.

Kuhn, R., \& Culhane, D. (1998). Applying cluster analysis to test a typology of homelessness by pattern of shelter utilization: Results from the analysis of administrative data. American Journal of Community Psychology, 26, 207-232.

Link, B., Phelan, J., Bresnahan, M., Stueve, A., Moore, R., \& Susser, E. (1995). Lifetime and five-year prevalence of homelessness in the United States: New Evidence on an Old Debate. American Journal of Orthopsychiatry, 65, 347-354.

Longabaugh, R., \& Eldred, S. (1973). Premorbid adjustments, schizoid personality and onset of illness as predictors of post-hospitalization functioning. Journal of Psychiatric Research, 10, 19-29.

McAdams, D. (1992). The intimacy motive. In Smith, C (Ed.), Motivation and Personality, Handbook of Thematic Content Analysis. New York: Cambridge University Press.

Mellsop, G. (1973). Antecedents of schizophrenia: The "schizoid" myth? Australian \& New Zealand Journal of Psychiatry, 7, 208-211.

Morse, G., \& Calsyn, R. (1986). Mentally disturbed homeless people in St. Louis: Needy, willing, but underserved. International Journal of Mental Health, 14, 74-94.

Morse, G., Calsyn, R., Allen, G., \& Kenny, D. (1994). Helping homeless mentally ill people: What variables mediate and moderate program effects. American Journal of Community Psychology, $22,661-683$.

Murray, R., Baier, M., North, C., Lato, M., \& Eskew, C. (1995). Components of an effective transitional residential program for homeless mentally ill clients. Archives of Psychiatric Nursing, 9, 152157.

National Coalition for the Homeless. (1999). NCH Fact Sheet \#2. Retrieved September 27, 1999 from the World Wide Web: http://nch.ari.net/members.html.

Nestadt, F., Liang, K, Lamacz, M., et al. (1994). An evaluation of the structure of schizophrenia spectrum disorders. Journal of Personality Disorders, 8, 288-298.

Orwin, R., Sonnefeld, L., Garrison-Mogren, R., \& Smith, N. (1994). Pitfalls in evaluating the effectiveness of case management programs for homeless persons: Lessons from the NIAAA community demonstration program. Evaluation Review, 18, 153-207.

Passero, J., Zax, M., \& Zozus, R. (1991). Social network utilization as related to family history among the homeless. Journal of Community Psychology, 19, 70-78.

Reich, J., Yates, W., \& Nduaguba, M. (1989). Prevalence of DSM-III personality disorders in the community. Social Psychiatry \& Psychiatric Epidemiology, 24, 12-16.

Robertson, M. (1986). Mental disorder among homeless persons in the United States: An overview of recent empirical literature. Administration in Mental Health, 14, 14-27.

Rosenheck, R., \& Leda, C. (1991). Who is served by programs for the homeless? Admission to a domiciliary care program for homeless veterans. Hospital and Community Psychiatry, 42, 176181.

Rosenheck, R., Leda, C., \& Gallup, P. (1992). Combat stress, psychosocial adjustment, and service use among homeless Vietnam veterans. Hospital and Community Psychiatry, 43, 145-149.

Rossi, P., Wright, J., Fisher, G., \& Willis, G. (1987). The urban homeless: estimating composition and size. Science, 23, 1336-1341.

Schumacher, J. Milby, J. B., Raczynski, J. M., \& Caldwell, E. (1995). Validity of self-reported crack cocaine users among homeless persons in treatment. Journal of Substance Abuse Treatment, 12, $335-339$.

Scott, J. (1993). Homelessness and mental illness. British Journal of Psychiatry, 162, 314-324.

Slagg, N., Lyons, J., Cook, J., Wasner, D., \& Ruth, A. (1994). A profile of clients served by a mobile 
outreach program for the homeless mentally ill. Hospital and Community Psychiatry, 45, 11391141.

Susser, E. (1991). Personal History Interview. New York: Author.

Torgalsboen, A. (1999). Comorbidity in schizophrenia: A prognostic study of personality disorders in recovered and non-recovered schizophrenia patients. Scandinavian Journal of Psychology, 40, $147-152$.

Westen, D. (1997). Divergences between clinical and research methods for assessing personality disorders: Implications for research and the evolution of Axis II. American Journal of Psychiatry, 154, 895-903.

Widiger, T. A., \& Rogers, J. H. (1989). Prevalence and comorbidity of personality disorders. Psychiatric Annals, 19, 132-136.

Zimmerman, M., \& Coryell, W. (1989). DSM-III personality disorder diagnoses in a nonpatient sample: Demographic correlates and comorbidity. Archives of General Psychiatry, 46, 682-689. 